Article

\title{
Optimal Bidding Strategies for Wind Power Producers in the Day-ahead Electricity Market
}

\section{Haifeng Zhang, Feng Gao, Jiang Wu *, Kun Liu and Xiaolin Liu}

State Key Laboratory for Manufacturing Systems Engineering, Systems Engineering Institute, Xi'an Jiaotong University, Xi'an 710049, China; E-Mails: hfzhang@sei.xjtu.edu.cn (H.Z.); fgao@sei.xjtu.edu.cn (F.G.); kliu@sei.xjtu.edu.cn (K.L.); xlliu@sei.xjtu.edu.cn (X.L.)

* Author to whom correspondence should be addressed; E-Mail: jwu@sei.xjtu.edu.cn; Tel.: +86-29-8266-7775; Fax: +86-29-8266-8677.

Received: 19 September 2012; in revised form: 13 November 2012 / Accepted: 13 November 2012 / Published: 20 November 2012

\begin{abstract}
Wind Power Producers (WPPs) seek to maximize profit and minimize the imbalance costs when bidding into the day-ahead market, but uncertainties in the hourly available wind and forecasting errors make the bidding risky. This paper assumes that hourly wind power output given by the forecast follows a normal distribution, and proposes three different bidding strategies, i.e., the expected profit-maximization strategy (EPS), the chance-constrained programming-based strategy (CPS) and the multi-objective bidding strategy (ECPS). Analytical solutions under the three strategies are obtained. Comparisons among the three strategies are conducted on a hypothetical wind farm which follows the Spanish market rules. Results show that bid under the EPS is highly dependent on market clearing price, imbalance prices, and also the mean value and standard deviation of wind forecast, and that bid under the CPS is largely driven by risk parameters and the mean value and standard deviation of the wind forecast. The ECPS combining both EPS and CPS tends to choose a compromise bid. Furthermore, the ECPS can effectively control the tradeoff between expected profit and target profit for WPPs operating in volatile electricity markets.
\end{abstract}

Keywords: wind power; bidding; day-ahead electricity market; risk; chance-constrained programming; multi-objective optimization 


\section{List of symbols}

$R \quad$ profit in single period [€], a random variable

$P_{b} \quad$ quantity bid into day-ahead market in single period [MW]

$P_{t} \quad$ real power generated by the concerned wind farm [MW]

$I_{c} \quad$ Imbalance costs in single period $[€]$

$P_{\max } \quad$ rated power of the concerned wind farm [MW]

$\lambda_{s} \quad$ day-ahead market price in single period [€/MWh]

$\lambda_{\text {sell }} \quad$ price of positive imbalances incurred in single period [ $€ / \mathrm{MWh}$ ]

$\lambda_{\text {buy }} \quad$ price of negative imbalances incurred in single period [ $\left.€ / \mathrm{MWh}\right]$

$\mu_{t} \quad$ mean value of wind power forecast in single period $t$ [MW]

$\delta_{t} \quad$ standard deviation of wind power forecast in single period $t$ [MW]

$J \quad$ target profit in single period[ $€]$

$\beta \quad$ confidence level, $\beta \in[0,1]$

$f\left(P_{t}\right) \quad$ probability density function of random variable $P_{t}$

$h(R) \quad$ probability density function of random variable $R$

$H(R) \quad$ cumulative distribution function of random variable $R$

$\operatorname{Pr}\{A\} \quad$ probability of event $A$

$F_{1}\left(P_{b}\right) \quad$ expected profit function in single period $[€]$

$F_{2}\left(P_{b}\right) \quad$ target profit function in single period [€]

$G\left(P_{b}\right) \quad$ weighted sum of $F_{1}\left(P_{b}\right)$ and $F_{2}\left(P_{b}\right)$

$\alpha \quad$ weight assigned to $G\left(P_{b}\right)$

$F_{i}^{\max } \quad$ maximal value of single objective, $i=1,2$

$F_{i}^{\text {min }} \quad$ minimal value of single objective, $i=1,2$

$u_{F_{i}} \quad$ membership function of $F_{i}$

$u_{D} \quad$ normalized membership function

$M \quad$ number of nondominated solutions

$N_{o b j} \quad$ number of objectives, in this article, $N_{o b j}=2$

\section{Introduction}

Encouraged by hospitable legal and financial policies, the worldwide installation of wind power has increased significantly over the past several years. In some markets like the Spanish market and Nordic power market, wind power producers (WPPs) have the option to bid in the electricity market or to sell all the energy to the market operator. When bidding into the electricity market, WPPs commit power production to the market operator for scheduling. However, due to the intermittency and unpredictability of wind power generation, the final power delivered usually differs from the power committed in the day-ahead market. This energy deviation results in imbalance costs, which must be paid by those who produce the wind power [1,2]. Although the accurate prediction of wind power generation (forecasted by WPPs) can reduce the imbalance costs to some extent, prediction precision is limited to the forecast length [3]; furthermore, optimal bids often do not coincide with the best predictions [4]. Thus, WPPs tend to find optimal bids which take into account both the maximal profit and minimal imbalance costs. 
As the installation capacity of wind power has increased in recent years, so have researchers' interests in proposing bidding strategies in the short-term electricity market for WPPs [5-9]. In [5], a bidding strategy using Markov probabilities for a wind farm in the United Kingdom to determine the best energy contract level was presented; this study demonstrated how a change in market closure delay and in the number of trades per day affects the overall expected imbalance costs for the wind farm. A probability density function representing the accuracy of the prediction model was defined as a Beta function in [6], and a probabilistic methodology to estimate the energy costs associated with the prediction errors was similarly proposed. Reference [7] presented a general methodology for deriving optimal bidding strategies based on probabilistic forecasts of wind production; modeling of the potential WPP sensitivity to regulation costs was also discussed. Matevosyan and Soder [8] utilized the ARMA model to simulate scenarios for wind speed forecasting errors, and developed a bidding strategy as a stochastic mixed integer programming problem to maximize expected profit and minimize the imbalance costs for WPPs. A stochastic programming approach was proposed to generate the optimal offers under untainty in wind generation and electricity prices [9].

The aforementioned literatures take into account the imbalance costs caused by the stochastic nature of wind, without considering however the risk that WPPs face with regard to the bidding process itself. Risk and profit are two conflicting objectives, as high profit is usually accompanied by high risk. It is critical for WPPs to be able to estimate their expected risk during the bidding process.

Optimal trading strategies for wind generation that consider the risk to power producers have been extensively researched [10-20]. In [10], different risk management approaches for wind trading in the electricity market were discussed, and the utility function method was considered to be more effective than the mean variance model. Xue et al. [11] defined the power producer's attitude towards risk as the membership function based on the fuzzy set theory, and subsequently proposed a multi-objective optimal bidding strategy; this fuzzy optimization method was extended to coordinated trading of wind generators and an energy storage device (ESD) in [12], which took into account the risk quantified by computing expected energy not served (EENS). Bidding strategies based on utility and the conditional value at risk $(\mathrm{CVaR})$ were derived to study the optimal bidding strategies for WPPs in $[13,14]$. Reference [15] developed optimal bidding strategy including various trading floors based on the scenario method, and $\alpha-\mathrm{CVaR}$ was used to calculate the expected profit of the $(1-\alpha) 100 \%$ scenarios with lowest profit similar to that reported in [16]. In [17], a CVaR constrained for the bid that maximized the expected revenue was proposed as a way of reducing the risk. Catalao et al. [18] provided a two-stage stochastic programming approach for WPPs considering uncertainties related to electricity market and wind power generation, and also incorporated the risk averion by limiting the volatility of the expected profit through the CVaR methodology. Reference [19] presented new analytical expressions for determining the optimal forward market strategy for wind generators under the risk-neutral and risk-averse cases, and the methods required spcification only of the expected real-time prices given the forward price and wind out-turn. Wang et al. [20] established a two-stage optimization model based on chance-constrained programming for unit commitment with uncertain wind power output, and described risk as the probability that a specific bidding strategy was accepted. In [21], a decision-making model for investing wind farm based on real options was presented and a risk profile characterization of the model was developed. These bidding strategy-specific studies provide a valuable framework for our own research in this field. 
In this article, hourly wind power output is assumed to follow a normal distribution [22-24], and three different bidding strategies are developed for WPPs to derive optimal day-ahead bids in the Spanish market. In fact, these strategies can be applied to any market with some minor adjustment. This article is organized as follows: A description of the problem, including the market framework and a basic model, is provided in Section 2. Section 3 describes the modeling details of three different bidding strategies, along with proposed model-specific solutions. Bidding results are compared in a case study in Section 4. Lastly, Section 5 summarizes our conclusions.

\section{Problem Description}

\subsection{Market Framework}

Consider a pool-based electricity market in which power suppliers submit day-ahead bids for each hour before closure of the day-ahead market (e.g., 10 AM). Unlike conventional generators, WPPs are generally regarded as price-takers, and are often not allowed to bid multiple price/quantity pairs. After a certain time of day (e.g., 3 PM), the market operator aggregates the hourly bids to determine the hourly market clearing prices $\left(\lambda_{s}, \mathrm{MCPs}\right)$ and the volumes being traded by identifying the point at which the supply bids and demand cross. Afterwards, the balancing market is carried out closer to real-time; this helps ensure that there is a real-time balance between generation and demand by offsetting the deviations between the real-time generation and the energy program cleared in the day-ahead market [15]. With such a market structure, the gap between the time at which the bids are submitted and the beginning of the energy delivery period is 14-38 hours [8]; the wind power forecast length should also be within this range. Because of the significant time gap, some markets include an intra-day market, where all producers correct their bids using more recent and accurate predictions. These actions are intended to reduce the differences between the expected production and the schedule cleared in the day-ahead market.

The objective of WPPs is to maximize their expected profits from trading energy in the day-ahead market while also minimizing the imbalance costs incurred in the balancing market. Different markets apply different imbalance penalty rules. In the Spanish market, the price for the positive energy deviation (higher real-time generation than scheduled) $\lambda_{\text {sell }}$ and the price for the negative energy deviation (lower real-time generation than the energy program cleared) $\lambda_{b u y}$ are settled for each hour. The imbalance price mechanism depends on the sign of imbalance of the whole system imbalance [15]. Specifically, when the system imbalance is positive (generation is greater than demand), those suppliers who generate more power than scheduled are penalized by $\lambda_{\text {sell }}$, while those who generate less power than scheduled are not penalized. These latter sellers help to alleviate the positive system imbalance and are paid by $\lambda_{s}$. The opposite holds true when the system imbalance is negative, (i.e., generation is less than demand).

From the above imbalance mechanism, a reasonable relation among $\lambda_{s}, \lambda_{\text {sell }}$ and $\lambda_{\text {buy }}$ can be expressed in the following inequation [11]:

$$
0 \leq \lambda_{\text {sell }} \leq \lambda_{s} \leq \lambda_{\text {buy }}
$$

In this paper, we don't focus on the prediction of prices, market clearing prices and the imbalance prices are considered to be given data, which can be derived from prediction models. 


\subsection{Profit of Wind Power Producers}

Consider a WPP that bids the quantity of $p_{b}$ into the day-ahead market for period $t$, but actually generates $p_{t}$. Since there are no inter-temporal constraints [8], we can formulate an hourly bidding problem. Solving the problem for each hour will give a day-ahead bidding strategy. The profit of the WPP for period $t$ is described as follows:

$$
R=p_{b} \lambda_{s}+I_{c}
$$

where $R$ is the profit which means the income from all markets, not the profit after taking into account production costs of generation. $I_{c}$ is the imbalance costs resulting from the balancing process. Here, $I_{c}$ is given by:

$$
I_{c}= \begin{cases}\lambda_{\text {buy }}\left(p_{t}-p_{b}\right), & p_{t} \leq p_{b} \\ \lambda_{\text {sell }}\left(p_{t}-p_{b}\right), & p_{t}>p_{b}\end{cases}
$$

Note that $p_{t}$ is a random variable and cannot be obtained in day-ahead. We assume that it follows normal distribution [22-24]. Then we have:

$$
p_{t} \sim N\left(\mu_{t}, \delta_{t}^{2}\right)
$$

The mean value $\mu_{t}$ and the standard deviation $\delta_{t}$ of hourly wind power forecast are assumed to be given data.

\section{Mathematical Formulation}

This section proposes three different bidding strategies for wind power producers to use when participating in the day-ahead market, i.e., the expected profit-maximization strategy (EPS), the chance-constrained programming-based strategy (CPS) and the multi-objective bidding strategy (ECPS). The EPS aims to maximize the expected profit and is a risk-neutral strategy. The CPS calculates the maximum target profit considering the risk which is defined as the probability that target profit cannot be realized. The ECPS combines the EPS and the CPS, and is formulated as a multi-objective model.

\subsection{Expected Profit-Maximization Bidding Strategy}

Let us denote the probability density function (PDF) by $f\left(p_{t}\right)$; in turn, this gives us an expected profit of a WPP as follows:

$$
\begin{aligned}
E[R] & =p_{b} \lambda_{s}+E\left[I_{c}\right] \\
& =p_{b} \lambda_{s}+\int_{-\infty}^{p_{b}}\left(p_{t}-p_{b}\right) \lambda_{\text {buy }} f\left(p_{t}\right) d p_{t}+\int_{p_{b}}^{+\infty}\left(p_{t}-p_{b}\right) \lambda_{\text {sell }} f\left(p_{t}\right) d p_{t}
\end{aligned}
$$

where $E[R]$ is the mathematical expectation of the random variable $R$. The right side of the equal sign in (5) is a function of $p_{b}$, and we denote it by:

$$
F_{1}\left(p_{b}\right)=p_{b} \lambda_{s}+\int_{-\infty}^{p_{b}}\left(p_{t}-p_{b}\right) \lambda_{\text {buy }} f\left(p_{t}\right) d p_{t}+\int_{p_{b}}^{+\infty}\left(p_{t}-p_{b}\right) \lambda_{\text {sell }} f\left(p_{t}\right) d p_{t}
$$

Thus, the EPS could be derived by maximizing $F_{1}\left(p_{b}\right)$, as shown in (7): 


$$
\begin{aligned}
& \max _{p_{b}} F_{1}\left(p_{b}\right) \\
& \text { s.t. } 0 \leq p_{b} \leq p_{\text {max }}
\end{aligned}
$$

The first derivative and the second derivative of objective function $F_{1}\left(p_{b}\right)$ are shown in (8) and (9):

$$
\begin{gathered}
d F_{1}\left(p_{b}\right) / d p_{b}=\lambda_{s}-\lambda_{\text {buy }} \int_{-\infty}^{p_{b}} f\left(p_{t}\right) d p_{t}-\lambda_{\text {sell }} \int_{p_{b}}^{+\infty} f\left(p_{t}\right) d p_{t} \\
d^{2} F_{1}\left(p_{b}\right) / d p_{b}^{2}=-\lambda_{\text {buy }} f\left(p_{b}\right)+\lambda_{\text {sell }} f\left(p_{b}\right)
\end{gathered}
$$

It can be seen that $d^{2} F\left(P_{b}\right) / d p_{\mathrm{b}}^{2} \leq 0$ in (9), so $F_{1}\left(P_{b}\right)$ is concave in $P_{b}$. The model in (7) can be easily solved; its optimal solutions are listed in (10) below:

$$
p_{b}^{*}=\left\{\begin{array}{l}
\text { arbitrary, } p_{b}^{*} \in\left[0, p_{\max }\right], \quad \lambda_{\text {sell }}=\lambda_{s}=\lambda_{\text {buy }} \\
\Phi^{-1}\left(\frac{\lambda_{s}-\lambda_{\text {sell }}}{\lambda_{\text {buy }}-\lambda_{\text {sell }}}\right) \delta_{t}+\mu_{t}, \quad \lambda_{\text {sell }}+\left(\lambda_{\text {buy }}-\lambda_{\text {sell }}\right) \Phi\left(-\frac{\mu_{t}}{\delta_{t}}\right) \leq \lambda_{s} \leq \lambda_{\text {sell }}+\left(\lambda_{\text {buy }}-\lambda_{\text {sell }}\right) \Phi\left(\frac{p_{\text {max }}-\mu_{t}}{\delta_{t}}\right) \\
0, \quad \lambda_{s}<\lambda_{\text {sell }}+\left(\lambda_{\text {buy }}-\lambda_{\text {sell }}\right) \Phi\left(-\frac{\mu_{t}}{\delta_{t}}\right) \\
p_{\text {max }}, \quad \lambda_{s}>\lambda_{\text {sell }}+\left(\lambda_{\text {buy }}-\lambda_{\text {sell }}\right) \Phi\left(\frac{p_{\max }-\mu_{t}}{\delta_{t}}\right)
\end{array}\right.
$$

where $\Phi(x)$ is the standard normal distribution function, and $\Phi^{-1}(x)$ is the inverse function of $\Phi(x)$.

From (9), we know that under EPS, the optimal bids are related to the MCP, imbalance prices, mean value, and standard deviation of wind power. The optimal objective $F_{1}\left(P_{b}^{*}\right)$ can also be easily calculated. The EPS does not consider risk faced by WPPs, so it is also called a risk-neutral strategy.

\subsection{Chance-Constrained Programming-Based Bidding Strategy}

In this section, we propose a chance-constrained programming-based bidding considering risk faced by WPPs in bidding process.

\subsubsection{Cumulative Distribution of Random Variable $R$}

From (2), (3), and (4), we get:

$$
R= \begin{cases}\left(\lambda_{s}-\lambda_{\text {sell }}\right) p_{b}+\lambda_{\text {sell }} p_{t}, & p_{b} \leq p_{t} \\ \left(\lambda_{s}-\lambda_{\text {buy }}\right) p_{b}+\lambda_{\text {buy }} p_{t}, & p_{t}>p_{b}\end{cases}
$$

It is known that $R$ is a random function of $P_{t}$ with a given $P_{b}$, and that it follows the normal distribution with the following distributed parameters:

$$
R \sim \begin{cases}N\left(\left(\lambda_{s}-\lambda_{\text {buy }}\right) p_{b}+\lambda_{\text {buy }} \mu_{t}, \lambda_{\text {buy }}^{2} \delta_{t}^{2}\right), & R \leq \lambda_{s} p_{b} \\ N\left(\left(\lambda_{s}-\lambda_{\text {sell }}\right) p_{b}+\lambda_{\text {sell }} \mu_{t}, \lambda_{\text {sell }}^{2} \delta_{t}^{2}\right), & R>\lambda_{s} p_{b}\end{cases}
$$

As is commonly known, the cumulative distribution of a random variable should be equal to 1 . However, the cumulative distribution of a variable $y$ with similar distributed parameters as shown in (11) may not be equal to 1 . For example, assuming that $x$ follows normal distribution i.e., $x \sim N(0,1)$, considering $y=\left\{\begin{array}{ll}x, & x \leq 5 \\ 2 x-5, & x>5\end{array}\right.$, then we obtain that $y$ follows the normal distribution $(y \sim N(0,1))$ when 
$x \leq 5$, and that $y$ follows the normal distribution $(y \sim N(0,4))$ when $x>5$. However, this is not true, because $\int_{-\infty}^{+\infty} y f(y) \neq 1$. So, the cumulative distribution of $R$ must be discussed.

For simplicity, let us introduce the following notations $h(R)$ and $H(R)=\left\{\begin{array}{l}H_{1}(R), R \leq \lambda_{s} p_{b} \\ H_{2}(R), R>\lambda_{s} p_{b}\end{array}\right.$ as representations of the PDF and cumulative distribution function (CDF) of $R$. A schematic diagram of the PDF of $R$ is shown in Figure 1.

Figure 1. A schematic diagram of the PDF of $R$.

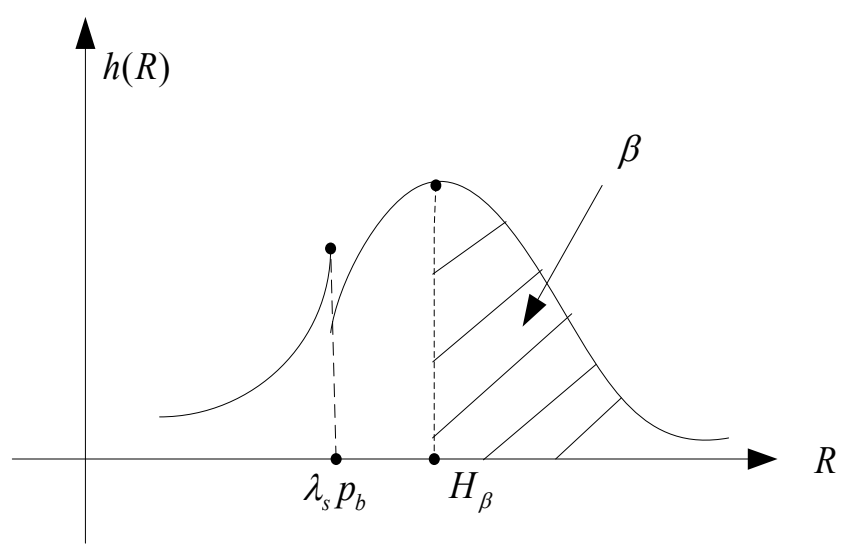

Let $\operatorname{Pr}\left\{R \leq \lambda_{s} P_{b}\right\}=\rho_{1}$ and $\operatorname{Pr}\left\{R>\lambda_{s} P_{b}\right\}=\rho_{2}$. From $\operatorname{Pr}\left\{R \leq \lambda_{s} P_{b}\right\}=\rho_{1}$, we are able to ascertain that $\lambda_{s} P_{b}$ is the lower quantile of $R$ i.e., $H_{1}\left(\lambda_{s} P_{b}\right)=\rho_{1}$, after normalizing $H_{1}\left(\lambda_{s} P_{b}\right)$, results in $\Phi\left(\frac{\lambda_{s} p_{b}-\left(\left(\lambda_{s}-\lambda_{\text {buy }}\right) p_{b}+\lambda_{\text {buy }} \mu_{t}\right)}{\lambda_{\text {buy }} \delta_{t}}\right)=\rho_{1}$, i.e., $\rho_{1}=\Phi\left(\frac{p_{b}-\mu_{t}}{\sigma_{t}}\right)$. Similarly, from $\operatorname{Pr}\left\{R>\lambda_{s} P_{b}\right\}=\rho_{2}$, we have $\rho_{2}=1-\Phi\left(\frac{p_{b}-\mu_{t}}{\sigma_{t}}\right)$. Since $\rho_{1}+\rho_{2}=1$, the cumulative distribution of $R$ is thus equal to 1 .

\subsubsection{Formulation of the CPS}

The model (7) only takes into account the expected profit without considering the risk faced by a WPP in the bidding process. As previously noted, higher profit is usually accompanied by higher risk. In this section, risk is defined as the probability that the target profit cannot be realized. Here we introduce a chance-constrained programming-based bidding model to obtain the CPS as formulated in (13):

$$
\left\{\begin{array}{l}
\max _{p_{b}} \bar{J} \\
\text { s.t. } \operatorname{Pr}\{R \geq \bar{J}\} \geq \beta \\
0 \leq p_{b} \leq p_{\max }
\end{array}\right.
$$

where $\bar{J}$ is the target profit, and $\beta$ is the probability that $\bar{J}$ can be realized. Definitions of other parameters can be found in the section above.

Rewrite $\operatorname{Pr}\{R \geq \bar{J}\} \geq \beta$ as follows:

$$
\operatorname{Pr}\{R \leq \bar{J}\} \leq 1-\beta
$$


$1-\beta$ describes the risk that the target profit cannot be realized; this varies from 0 to 1 . The model (13) proposed a method to measure risk quantitatively.

Now we discuss the general solution for the optimization problem in the model. From Figure 1, when $H^{-1}(1-\beta) \geq \lambda_{s} P_{b}$, we have:

$$
\frac{\lambda_{s} p_{b}-\mu_{r}}{\delta_{r}} \leq \Phi^{-1}(1-\beta)
$$

where $\mu_{r}$ and $\delta_{r}$ can take any distributed parameter of (12), and $\Phi^{-1}(1-\beta)$ is the upper quantile of a standard normal distribution, then we get $p_{b} \leq \Phi^{-1}(1-\beta) \delta_{t}+\mu_{t}$. Under this condition, the maximal $\bar{J}$ should be greater than or equal to $\lambda_{s} P_{b}$; thus, $R$ follows the below distribution i.e., $\mathrm{R} \sim \mathrm{N}\left(\left(\lambda_{s}-\lambda_{\text {sell }}\right) p_{b}+\lambda_{\text {sell }} \mu_{t}, \lambda_{\text {sell }}^{2} \delta_{t}^{2}\right)$, resulting in:

$$
\frac{\bar{J}-\left[\left(\lambda_{s}-\lambda_{\text {sell }}\right) p_{b}+\lambda_{\text {sell }} \mu_{t}\right]}{\lambda_{\text {sell }} \delta_{t}} \leq \Phi^{-1}(1-\beta)
$$

i.e., $\bar{J} \leq \Phi^{-1}(1-\beta) \lambda_{\text {sell }} \delta_{t}+\left(\lambda_{s}-\lambda_{\text {sell }}\right) p_{b}+\lambda_{\text {sell }} \mu_{t}$.

Similarly, when $H^{-1}(1-\beta)<\lambda_{s} P_{b}$, we have $p_{b} \geq \Phi^{-1}(1-\beta) \delta_{t}+\mu_{t}$, and $R$ follows the normal distribution below, i.e., $\mathrm{R} \sim \mathrm{N}\left(\left(\lambda_{s}-\lambda_{b u y}\right) p_{b}+\lambda_{b u y} \mu_{t}, \lambda_{b u y}^{2} \delta_{t}^{2}\right)$, then we get $\bar{J} \leq \Phi^{-1}(1-\beta) \lambda_{\text {buy }} \delta_{t}+\left(\lambda_{s}-\lambda_{\text {buy }}\right) p_{b}+\lambda_{\text {buy }} \mu_{t}$.

From the above discussion, we learn that maximal $\bar{J}$ is a function of $p_{b}$; thus, let us denote:

$$
F_{2}\left(p_{b}\right)=\left\{\begin{array}{lc}
\Phi^{-1}(1-\beta) \lambda_{\text {sell }} \delta_{t}+\left(\lambda_{s}-\lambda_{\text {sell }}\right) p_{b}+\lambda_{\text {sell }} \mu_{t}, & 0 \leq p_{b} \leq \Phi^{-1}(1-\beta) \delta_{t}+\mu_{t} \\
\Phi^{-1}(1-\beta) \lambda_{\text {buy }} \delta_{t}+\left(\lambda_{s}-\lambda_{\text {buy }}\right) p_{b}+\lambda_{\text {buy }} \mu_{t}, & \Phi^{-1}(1-\beta) \delta_{t}+\mu_{t}<p_{b} \leq P_{\max }
\end{array}\right.
$$

Then the model (13) can be transformed into the model (18) as follows:

$$
\left\{\begin{array}{l}
\max _{p_{b}} F_{2}\left(p_{b}\right) \\
\text { s.t. } 0 \leq p_{b} \leq p_{\max }
\end{array}\right.
$$

Figure 2 shows $F_{2}\left(p_{b}\right)$ as a function of $p_{b}$. It is not difficult to obtain the analytical solutions of model (18); the results of these calculations are listed in Table 1.

Figure 2. Function $F_{2}$ versus $P_{b}$.

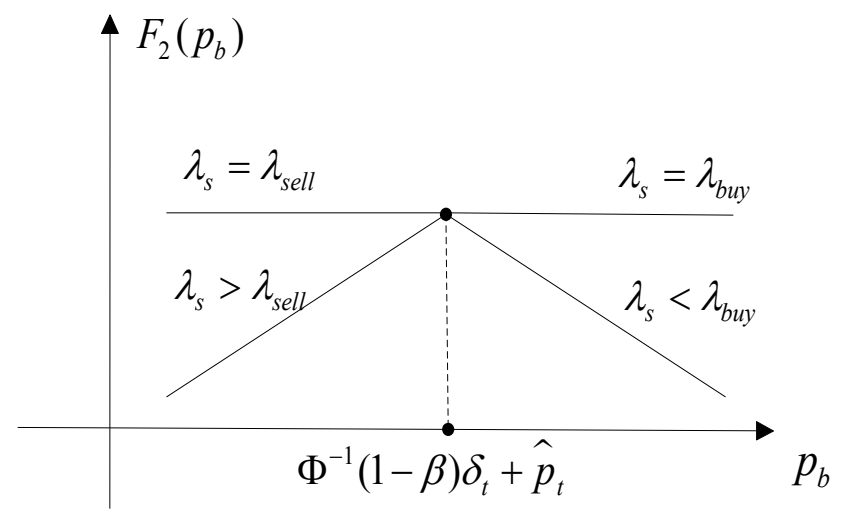


Table 1. Optimal results of chance-constrained programming-based bidding model.

\begin{tabular}{|c|c|c|c|}
\hline Range of $\beta$ & $\begin{array}{c}\text { Relationship } \\
\text { among } \lambda_{s}, \lambda_{\text {sell }} \\
\text { and } \lambda_{\text {buy }}\end{array}$ & Optimal solution, $P_{b}^{*}$ & $F_{2}\left(P_{b}^{*}\right)$ \\
\hline \multirow{3}{*}{$0,1-\Phi\left(\frac{p_{\max }-\mu_{t}}{\delta_{t}}\right)$} & & & $\Phi^{-1}(1-\beta) \lambda_{\text {sell }} \delta_{t}+$ \\
\hline & $\lambda_{s}>\lambda_{\text {sell }}$ & $p_{\text {max }}$ & $\left(\lambda_{s}-\lambda_{\text {sell }}\right) p_{\max }+\lambda_{\text {sell }} \mu_{t}$ \\
\hline & $\lambda_{s}=\lambda_{\text {sell }}$ & $\forall p_{b}^{*} \in\left[0, p_{\max }\right]$ & $\lambda_{s}\left[\Phi^{-1}(1-\beta) \delta_{t}+\mu_{t}\right]$ \\
\hline \multirow{2}{*}{$\left(1-\Phi\left(\frac{-\mu_{t}}{\delta_{t}}\right), 1\right]$} & $\lambda_{s}<\lambda_{b u y}$ & 0 & $\Phi^{-1}(1-\beta) \lambda_{\text {buy }} \delta_{t}+\lambda_{\text {buy }} \mu_{t}$ \\
\hline & $\lambda_{s}=\lambda_{b u y}$ & $\forall p_{b}^{*} \in\left[0, p_{\max }\right]$ & $\lambda_{s}\left[\Phi^{-1}(1-\beta) \delta_{t}+\mu_{t}\right]$ \\
\hline \multirow{4}{*}[1-\Phi(\frac{p_{\operatorname{max}}-\mu_{t}}{\delta_{t}}),1-\Phi(\frac{-\mu_{t}}{\delta_{t}})]{} & $\lambda_{\text {sell }}=\lambda_{s}=\lambda_{b u y}$ & $\forall p_{b}^{*} \in\left[0, p_{\max }\right]$ & $\lambda_{s}\left[\Phi^{-1}(1-\beta) \delta_{t}+\mu_{t}\right]$ \\
\hline & $\lambda_{\text {sell }}=\lambda_{s}<\lambda_{\text {buy }}$ & $\forall p_{b}^{*} \in\left[0, \Phi^{-1}(1-\beta) \delta_{t}+\mu_{t}\right]$ & $\lambda_{s}\left[\Phi^{-1}(1-\beta) \delta_{t}+\mu_{t}\right]$ \\
\hline & $\lambda_{\text {sell }}<\lambda_{s}=\lambda_{b u y}$ & $\forall p_{b}^{*} \in\left[\Phi^{-1}(1-\beta) \delta_{t}+\mu_{t}, p_{\max }\right]$ & $\lambda_{s}\left[\Phi^{-1}(1-\beta) \delta_{t}+\mu_{t}\right]$ \\
\hline & $\lambda_{\text {sell }}<\lambda_{s}<\lambda_{\text {buy }}$ & $\Phi^{-1}(1-\beta) \delta_{t}+\mu_{t}$ & $\lambda_{s}\left[\Phi^{-1}(1-\beta) \delta_{t}+\mu_{t}\right]$ \\
\hline
\end{tabular}

It can be seen from Table 1 that the optimal bids under the CPS are related to $\beta$, prices, and the distributed parameters.

\subsection{Multi-Objective Bidding Strategy}

\subsubsection{Multi-Objective Bidding Model}

In this section, we present ECPS based on a multi-objective bidding model that takes into account both expected profit and risk. The multi-objective model is formulated as follows:

$$
\left\{\begin{array}{l}
\max _{p_{b}}\left[F_{1}\left(p_{b}\right), F_{2}\left(p_{b}\right)\right] \\
\text { s.t. } 0 \leq p_{b} \leq p_{\max }
\end{array}\right.
$$

where $F_{1}\left(p_{b}\right)$ and $F_{2}\left(p_{b}\right)$ are as defined in Sections 3.1 and 3.2. Since $F_{1}\left(p_{b}\right)$ and $F_{2}\left(p_{b}\right)$ are concave functions, we convert the problem to a single-function objective through the weighted sum of the objective functions (19)-(20):

$$
\begin{gathered}
\left\{\begin{array}{l}
\max _{p_{b}} G\left(p_{b}\right) \\
\text { s.t. } 0 \leq p_{b} \leq p_{\text {max }}
\end{array}\right. \\
G\left(p_{b}\right)=(1-\alpha) F_{1}\left(p_{b}\right)+\alpha F_{2}\left(p_{b}\right)
\end{gathered}
$$

where $\alpha$ is the weight selected from [0.0 1.0]. A set of non-dominated solutions can be obtained by varying $\alpha$ through this weighted sum method. When $\alpha=0$, the model (20) changes into the model (7), and when $\alpha=1$, it changes into the model (18). Furthermore, model (20) is expressed as shown below:

When $p_{b} \geq \Phi^{-1}(1-\beta) \delta_{t}+\mu_{t}$, (20) can be rewritten as follows:

$$
\left\{\begin{array}{l}
\max _{p_{b}} G_{1}\left(p_{b}\right) \\
\text { s.t. } 0 \leq p_{b} \leq p_{\max }
\end{array}\right.
$$

where $G_{1}\left(p_{b}\right)=\alpha\left[\Phi^{-1}(1-\beta) \lambda_{\text {buy }} \delta_{t}+\left(\lambda_{s}-\lambda_{\text {buy }}\right) p_{b}+\lambda_{\text {buy }} \mu_{t}\right]+(1-\alpha) F_{1}\left(p_{b}\right)$. When $p_{b} \leq \Phi^{-1}(1-\beta) \delta_{t}+\mu_{t}$, (20) can be rewritten as follows: 


$$
\left\{\begin{array}{l}
\max _{p_{b}} G_{2}\left(p_{b}\right) \\
\text { s.t. } 0 \leq p_{b} \leq p_{\max }
\end{array}\right.
$$

where $G_{2}\left(p_{b}\right)=\alpha\left[\Phi^{-1}(1-\beta) \lambda_{\text {sell }} \delta_{t}+\left(\lambda_{s}-\lambda_{\text {sell }}\right) p_{b}+\lambda_{\text {sell }} \hat{p}_{t}\right]+(1-\alpha) F_{1}\left(p_{b}\right)$. The first derivative and second derivative of the objective functions $G_{1}\left(p_{b}\right)$ and $G_{2}\left(p_{b}\right)$ are shown below:

$$
\begin{gathered}
d G_{1}\left(p_{b}\right) / d p_{b}=\lambda_{s}-\alpha \lambda_{\text {buy }}-(1-\alpha) \lambda_{\text {buy }} \int_{-\infty}^{p_{b}} f\left(p_{t}\right) d p_{t}-(1-\alpha) \lambda_{\text {sell }} \int_{p_{b}}^{+\infty} f\left(p_{t}\right) d p_{t} \\
d G_{2}\left(p_{b}\right) / d p_{b}=\lambda_{s}-\alpha \lambda_{\text {sell }}-(1-\alpha) \lambda_{\text {buy }} \int_{-\infty}^{p_{b}} f\left(p_{t}\right) d p_{t}-(1-\alpha) \lambda_{\text {sell }} \int_{p_{b}}^{+\infty} f\left(p_{t}\right) d p_{t} \\
d^{2} G_{1}\left(p_{b}\right) / d p_{b}^{2}=-(1-\alpha) \lambda_{\text {buy }} f\left(p_{b}\right)+(1-\alpha) \lambda_{\text {sell }} f\left(p_{b}\right) \leq 0 \\
d^{2} G_{2}\left(p_{b}\right) / d p_{b}^{2}=-(1-\alpha) \lambda_{\text {buy }} f\left(p_{b}\right)+(1-\alpha) \lambda_{\text {sell }} f\left(p_{b}\right) \leq 0
\end{gathered}
$$

The solutions of the models (22) and (23) are presented in the next section.

\subsubsection{Solution of Multi-objective Bidding Model}

In this section, the general solution for a multi-objective bidding model is developed, and the solution is also analyzed in detail for several cases. Specifically, the following details are presented:

(1) $\lambda_{\text {sell }}=\lambda_{s}=\lambda_{\text {buy }}$

Since $d G_{1}\left(p_{b}\right) / d p_{b}=d G_{2}\left(p_{b}\right) / d p_{b}=0$, thus, $\forall \beta \in[0,1]$ and the optimal bid is arbitrary $p_{b}^{*}$, and $p_{b}^{*} \in\left[0, p_{\max }\right]$, and the maximal value of each objective: $F_{l}^{*}=\lambda_{s} \mu_{t}, F_{2}^{*}=\lambda_{s}\left[\Phi^{-1}(1-\beta) \delta_{t}+\mu_{t}\right]$.

(2) $\lambda_{\text {sell }}<\lambda_{\text {buy }}$

Case (1) $\Phi^{-1}(1-\beta) \delta_{t}+\mu_{t}<0$, i.e., $0 \leq 1-\beta<\Phi\left(-\frac{\mu_{t}}{\delta_{t}}\right)$

If $0 \leq p_{b} \leq p_{\max }$, we apply the model (22). For simplicity, let us denote $\int_{-\infty}^{p_{b}} f\left(p_{t}\right) d p_{t}=z_{1}$, then $d G_{1}\left(p_{b}\right) / d p_{b}=\lambda_{s}-\alpha \lambda_{b u y}-(1-\alpha) \lambda_{b u y} z_{1}-(1-\alpha) \lambda_{\text {sell }}\left(1-z_{1}\right)$.

- Case (1a) if $\lambda_{\text {sell }} \leq \lambda_{s}<\alpha \lambda_{\text {buy }}+(1-\alpha) \lambda_{\text {sell }}$, we have $d g_{1}\left(p_{b}\right) / d p_{b}<0$, the function $G_{1}\left(p_{b}\right)$ is monotonically decreasing, we get $p_{b}^{*}=0$, and $G_{l}^{*}=G_{1}(0)$.

- Case (1b) if $\alpha \lambda_{\text {buy }}+(1-\alpha) \lambda_{\text {sell }} \leq \lambda_{s} \leq \lambda_{\text {buy }}$, from, $d g_{1}\left(p_{b}\right) / d p_{b}=0$, we have $z_{1}=\frac{\lambda_{s}-\alpha \lambda_{\text {buy }}-(1-\alpha) \lambda_{\text {sell }}}{(1-\alpha)\left(\lambda_{\text {buy }}-\lambda_{\text {sell }}\right)}$, and $0 \leq z_{1} \leq 1$, the extreme point $p_{b}=\Phi^{-1}\left(z_{1}\right) \delta_{t}+\mu_{t}$. Three cases are considered further: if $\Phi^{-1}\left(z_{1}\right) \delta_{t}+\mu_{t}<0, p_{b}^{*}=0, G_{l}^{*}=G_{1}(0)$;

if $0 \leq \Phi^{-1}\left(z_{1}\right) \delta_{t}+\mu_{t} \leq p_{\max }, p_{b}^{*}=\Phi^{-1}\left(z_{1}\right) \delta_{t}+\mu_{t}, G_{l}^{*}=G_{1}\left(\Phi^{-1}\left(z_{1}\right) \delta_{t}+\mu_{t}\right)$;

if $\Phi^{-1}\left(z_{1}\right) \delta_{t}+\mu_{t}>p_{\max }, p_{b}^{*}=p_{\max }, G_{1}^{*}=G_{1}\left(p_{\max }\right)$.

Case (2) $\Phi^{-1}(1-\beta) \delta_{t}+\mu_{t}>p_{\max }$, i.e., $\Phi\left(\frac{p_{\max }-\mu_{t}}{\delta_{t}}\right)<1-\beta \leq 1$

If $0 \leq p_{b} \leq p_{\max }$, we can apply the model (23). For simplicity, let us denote $\int_{-\infty}^{p_{b}} f\left(p_{t}\right) d p_{t}=z_{2}$ then $d g_{2}\left(p_{b}\right) / d p_{b}=\lambda_{s}-\lambda_{\text {sell }}-(1-\alpha)\left(\lambda_{\text {buy }}-\lambda_{\text {sell }}\right)$. 
- Case (2a) if $\left.(1-\alpha) \lambda_{b u y}+\alpha \lambda_{\text {sell }}\right) \leq \lambda_{s} \leq \lambda_{b u y}, d g_{1}\left(p_{b}\right) / d p_{b}>0$, the objective function is monotonically decreasing, we get $p_{b}^{*}=p_{\max }, G_{2}^{*}=G_{2}\left(p_{\max }\right)$.

- Case (2b) if $\lambda_{\text {sell }} \leq \lambda_{s} \leq(1-\alpha) \lambda_{\text {buy }}+\alpha \lambda_{\text {sell }}$, from $d g_{2}\left(p_{b}\right) / d p_{b}=0$, we have $z_{2}=\frac{\lambda_{s}-\lambda_{\text {sell }}}{(1-\alpha)\left(\lambda_{\text {buy }}-\lambda_{\text {sell }}\right)}$, and $0 \leq z_{2} \leq 1$. Three cases are considered further:

if $\Phi^{-1}\left(z_{2}\right) \delta_{t}+\mu_{t}<0, p_{b}^{*}=0, G_{2}^{*}=G_{2}(0)$;

if $0 \leq \Phi^{-1}\left(z_{2}\right) \delta_{t}+\mu_{t} \leq p_{\max }, p_{b}^{*}=\Phi^{-1}\left(z_{2}\right) \delta_{t}+\mu_{t}, G_{2}^{*}=G_{2}\left(\Phi^{-1}\left(z_{2}\right) \delta_{t}+\mu_{t}\right)$;

if $\Phi^{-1}\left(z_{2}\right) \delta_{t}+\mu_{t}>p_{\max }, p_{b}^{*}=p_{\max }$ and $G_{2}^{*}=G_{2}\left(p_{\max }\right)$.

Case (3) $0 \leq \Phi^{-1}(1-\beta) \delta_{t}+\mu_{t} \leq p_{\max }$, i.e., $\Phi\left(\frac{-\mu_{t}}{\delta_{t}}\right) \leq 1-\beta \leq \Phi\left(\frac{p_{\max }-\mu_{t}}{\delta_{t}}\right)$

Let us divide the interval $0 \leq p_{b} \leq p_{\max }$.into $0 \leq p_{b} \leq \Phi^{-1}(1-\beta) \delta_{t}+\mu_{t}$ and $\Phi^{-1}(1-\beta) \delta_{t}+\mu_{t} \leq p_{b} \leq p_{\max }$; thus, we can solve the models (22) and (23), respectively.

- Case (3a) $0 \leq p_{b} \leq \Phi^{-1}(1-\beta) \delta_{t}+\mu_{t}$

In this case, we apply model (23), and then two more cases are considered:

(i) if $(1-\alpha) \lambda_{\text {buy }}+\alpha \lambda_{\text {sell }} \leq \lambda_{s} \leq \lambda_{\text {buy }}$, the optimal bid is $p_{b}^{*}=\Phi^{-1}(1-\beta) \delta_{t}+\mu_{t}$, and $G_{2}^{*}=G_{2}\left(\Phi^{-1}(1-\beta) \delta_{t}+\mu_{t}\right)$

(ii) if $\lambda_{\text {sell }} \leq \lambda_{s} \leq(1-\alpha) \lambda_{\text {buy }}+\alpha \lambda_{\text {sell }}$. Three cases are considered further:

if $\Phi^{-1}\left(z_{2}\right) \delta_{t}+\mu_{t}<0, p_{b}^{*}=0, G_{2}^{*}=G_{2}(0)$;

if $0 \leq \Phi^{-1}\left(z_{2}\right) \delta_{t}+\mu_{t} \leq \Phi^{-1}(1-\beta) \delta_{t}+\mu_{t}, p_{b}^{*}=\Phi^{-1}\left(z_{2}\right) \delta_{t}+\mu_{t}$ and $G_{2}^{*}=G_{2}\left(\Phi^{-1}\left(z_{2}\right) \delta_{t}+\mu_{t}\right)$;

if $\Phi^{-1}\left(z_{2}\right) \delta_{t}+\mu_{t}>\Phi^{-1}(1-\beta) \delta_{t}+\mu_{t}, p_{b}^{*}=\Phi^{-1}(1-\beta) \delta_{t}+\mu_{t}$ and $G_{2}^{*}=G_{2}\left(\Phi^{-1}(1-\beta) \delta_{t}+\mu_{t}\right)$.

- Case (3b) $\Phi^{-1}(1-\beta) \delta_{t}+\mu_{t} \leq p_{b} \leq p_{\max }$

In this case, we apply the model (22). Similarly, as in Case (3a),

(i) if $\lambda_{\text {sell }} \leq \lambda_{s}<\alpha \lambda_{\text {buy }}+(1-\alpha) \lambda_{\text {sell }}$, the optimal bid is $p_{b}^{*}=\Phi^{-1}(1-\beta) \delta_{t}+\mu_{t}$, and $G_{1}^{*}=G_{1}\left(\Phi^{-1}(1-\beta) \delta_{t}+\mu_{t}\right)$.

(ii) if $\alpha \lambda_{\text {buy }}+(1-\alpha) \lambda_{\text {sell }} \leq \lambda_{s} \leq \lambda_{\text {buy }}$. Three cases are considered further:

if $\Phi^{-1}\left(z_{1}\right) \delta_{t}+\mu_{t}<\Phi^{-1}(1-\beta) \delta_{t}+\mu_{t}, p_{b}^{*}=\Phi^{-1}(1-\beta) \delta_{t}+\mu_{t}, G_{1}^{*}=G_{1}\left(\Phi^{-1}(1-\beta) \delta_{t}+\mu_{t}\right)$;

if $\Phi^{-1}(1-\beta) \delta_{t}+\mu_{t} \leq \Phi^{-1}\left(z_{1}\right) \delta_{t}+\mu_{t} \leq p_{\max }, p_{b}^{*}=\Phi^{-1}\left(z_{1}\right) \delta_{t}+\mu_{t}$ and $G_{1}^{*}=G_{1}\left(\Phi^{-1}\left(z_{1}\right) \delta_{t}+\mu_{t}\right)$;

if $\Phi^{-1}\left(z_{1}\right) \delta_{t}+\mu_{t}>p_{\max }, p_{b}^{*}=p_{\max }$, and $G_{1}^{*}=G_{1}\left(p_{\max }\right)$.

From the above discussion, we have shown that when $0 \leq \Phi^{-1}(1-\beta) \delta_{t}+\mu_{t} \leq p_{\max }$, the maximal value of the objective is $\max \left\{G_{1}\left(p_{b}^{*}\right), G_{2}\left(p_{b}^{*}\right)\right\}$, and that the corresponding $p_{b}^{*}$ is the optimal bid.

\subsubsection{Best Compromise Solution}

The solution obtained from the multi-objective model is a Pareto-optimal set of non-dominated solution, from which WPPs should choose a solution as the final decision. This section proposed a method based on fuzzy theory to determine the best compromise solution [25]. Each objective function of the $m$-th solution is represented by a membership function $u_{F_{i}}^{m}$ defined as: 


$$
u_{F_{i}}^{m}= \begin{cases}0 & F_{i} \leq F_{i}^{\min } \\ \frac{F_{i}-F_{i}^{\min }}{F_{i}^{\max }-F_{i}^{\min }} & F_{i}^{\min }<F_{i}<F_{i}^{\max } \\ 1 & F_{i} \geq F_{i}^{\max }\end{cases}
$$

where $F_{i}^{\max }$ is the objective value only considering objective $i$, and $F_{i}^{\min }$ is the objective value considering other objectives except objective $i$. Thus, we can obtain $0 \leq u_{F_{i}} \leq 1$, in which $u_{F_{i}}=1$ reflects that the decision maker is totally satisfied with the objective and $u_{F_{i}}=0$ reflects the opposite.

For each non-dominated solution $m$, the normalized membership function $u_{D}^{m}$ is calculated by:

$$
u_{D}^{m}=\frac{\sum_{i=1}^{N_{o b j}} u_{F_{i}}^{m}}{\sum_{m=1}^{M} \sum_{i=1}^{N_{o b j}} u_{F_{i}}^{m}}
$$

where $M$ is the number of non-dominated solutions. The best compromise solution is the one having the maximum of $u_{D}^{m}$.

\section{Numerical Simulation}

Simulations are performed on a hypothetical wind farm with an installed capacity of $200 \mathrm{MW}$. The bidding problem is analyzed for one day using 24 hourly cases which are general and representative. Hourly mean values and standard deviations of wind power for the day are assumed to be obtained from historical data as shown in Table 2 [23].

Table 2. Hourly expected value and standard deviation of day-ahead wind power forecast.

\begin{tabular}{cccccc}
\hline Hour & $\begin{array}{c}\text { Expected } \\
\text { value/MW }\end{array}$ & $\begin{array}{c}\text { Standard } \\
\text { deviation/MW }\end{array}$ & Hour & $\begin{array}{c}\text { Expected } \\
\text { value/MW }\end{array}$ & $\begin{array}{c}\text { Standard } \\
\text { deviation/MW }\end{array}$ \\
\hline 1 & 70.0 & 31.37 & 13 & 133.0 & 84.76 \\
2 & 45.5 & 27.32 & 14 & 129.5 & 87.06 \\
3 & 24.5 & 21.53 & 15 & 147.0 & 96.39 \\
4 & 28.0 & 24.61 & 16 & 140.0 & 97.62 \\
5 & 42.0 & 32.08 & 17 & 133.0 & 98.6 \\
6 & 59.5 & 40.5 & 18 & 108.5 & 92.18 \\
7 & 70.0 & 46.63 & 19 & 84.0 & 83.86 \\
8 & 80.5 & 52.49 & 20 & 77.0 & 82.92 \\
9 & 94.5 & 59.78 & 21 & 66.5 & 79.4 \\
10 & 112.0 & 68.26 & 22 & 42.0 & 65.2 \\
11 & 126.0 & 75.22 & 23 & 35.0 & 61.34 \\
12 & 139.5 & 80.23 & 24 & 63.0 & 84.53 \\
\hline
\end{tabular}

Hourly MCPs based on the spot prices on 08/03/2012 provided by the European Power Exchange (EPEX SPOT SE) [26] and the hypothetical imbalance prices which follow the relation set forth in (1) are listed in Table 3. Note that there is both an up- and down regulating price for each hour in Table 3, in fact, our strategies can still work when there is only either up- or down-regulation price for each hour. 
Table 3. Hourly day-ahead market price and imbalance prices.

\begin{tabular}{cccccccc}
\hline $\boldsymbol{t}$ & $\begin{array}{c}\lambda_{\boldsymbol{s}} \\
(\boldsymbol{(} / \mathbf{M W h})\end{array}$ & $\begin{array}{c}\lambda_{\text {sell }} \\
(\boldsymbol{€} / \mathbf{M W h})\end{array}$ & $\begin{array}{c}\lambda_{\text {buy }} \\
(\boldsymbol{\epsilon} / \mathbf{M W h})\end{array}$ & $\boldsymbol{t}$ & $\begin{array}{c}\lambda_{\boldsymbol{s}} \\
(\boldsymbol{€} / \mathbf{M W h})\end{array}$ & $\begin{array}{c}\lambda_{\text {sell }} \\
(\boldsymbol{\epsilon} / \mathbf{M W h})\end{array}$ & $\begin{array}{c}\lambda_{\text {buy }} \\
(\boldsymbol{\epsilon} / \mathbf{M W h})\end{array}$ \\
\hline 1 & 53.54 & 25.23 & 59.56 & 13 & 52.02 & 35.43 & 71.32 \\
2 & 49.72 & 24.12 & 62.69 & 14 & 49.72 & 36.65 & 68.56 \\
3 & 41.6 & 23.16 & 59.68 & 15 & 45.36 & 38.26 & 72.63 \\
4 & 38.1 & 20.16 & 55.79 & 16 & 42.57 & 37.42 & 74.2 \\
5 & 35.07 & 24.68 & 56.2 & 17 & 41.66 & 35.87 & 75.36 \\
6 & 38.2 & 27.56 & 61.32 & 18 & 45.63 & 34.39 & 67.74 \\
7 & 42.57 & 30.2 & 62.28 & 19 & 52.01 & 42.16 & 79.68 \\
8 & 49.72 & 32.59 & 65.2 & 20 & 59.28 & 40.68 & 74.8 \\
9 & 53.54 & 35.63 & 68.21 & 21 & 59.28 & 37.33 & 70.12 \\
10 & 53.54 & 38.65 & 70.81 & 22 & 53.54 & 32.1 & 66.37 \\
11 & 53.54 & 38.55 & 70.71 & 23 & 52.64 & 24.63 & 62.09 \\
12 & 53.54 & 39.1 & 73.36 & 24 & 45.92 & 27.65 & 65.07 \\
\hline
\end{tabular}

We first present results for one individual hour (i.e., period 2), looking at how the objective functions in the three tested bidding strategies change as functions of day-ahead bid quantity. Then, we discuss how the risk $1-\beta$ and standard deviation of wind power forecast affect optimal decision making. Finally, we calculate the optimal bidding decisions for all the hours of the day.

We first present results for one individual hour (i.e., period 2), looking at how the objective functions in the three tested bidding strategies change as functions of day-ahead bid quantity. Then, we discuss how the risk $1-\beta$ and standard deviation of wind power forecast affect optimal decision making. Finally, we calculate the optimal bidding decisions for all the hours of the day.

In period 2, the mean value and the standard deviation of wind power forecast are $45.5 \mathrm{MW}$ and 27.32 MW, respectively. MCP, the price for the positive energy, and the price for the negative energy are $49.72 € / \mathrm{MWh}, 24.12 € / \mathrm{MWh}$, and $62.69 € / \mathrm{MWh}$, respectively. Figure 3 shows the change trend of expected profit under EPS. The expected profit first increases and then decreases; the optimal bid quantity is $57.05 \mathrm{MW}$ and is greater than the mean value (45.5) in period 2. This shows that larger bid quantity does not lead to larger expected profit because of the imbalance costs, as is shown in Figure 4.

Figure 3. Expected profit under the EPS versus bid quantity.

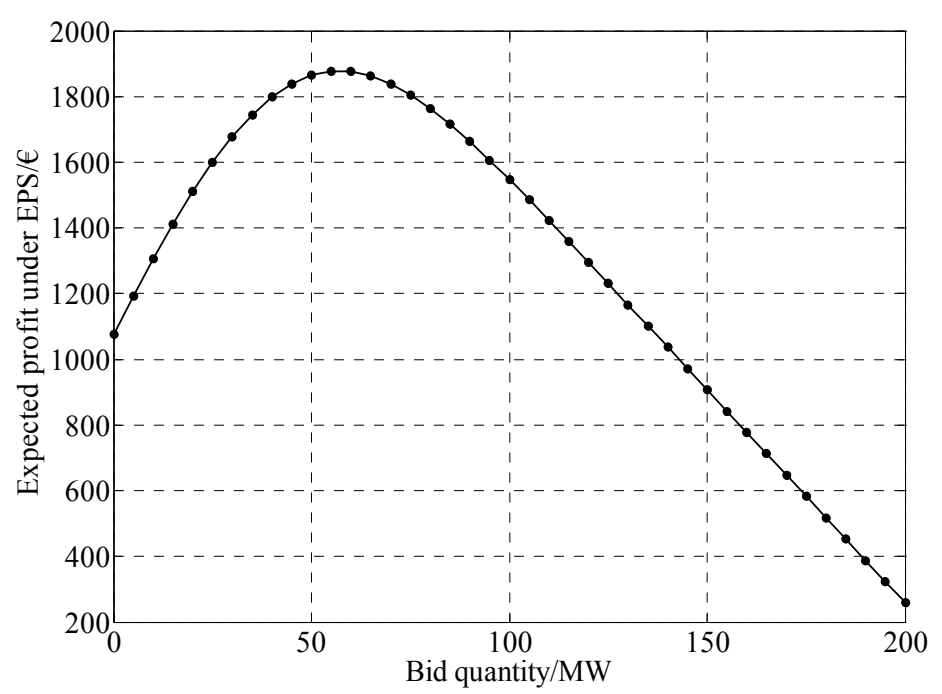


Figure 4. Imbalance costs versus bid quantity under the EPS.

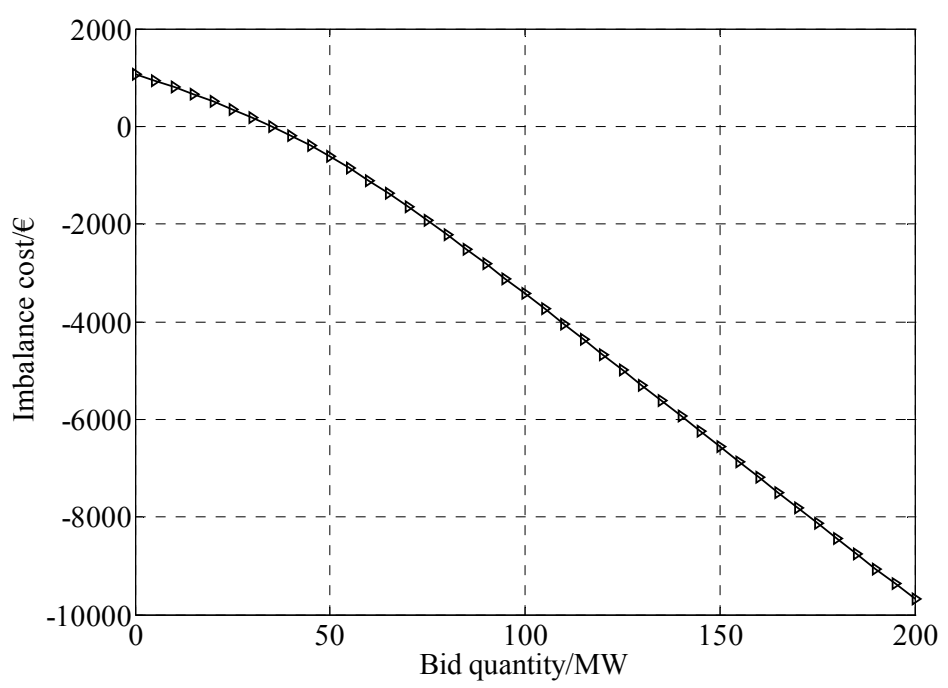

Figure 5 shows the change trend of target profit as a function of bid quantity with different risk parameters; due to the imbalance costs, it has a trend similar to that of expected profit under the EPS, and the optimal bid quantity under the CPS increases when the risk parameter increases.

The maximal optimal bid quantity with different $1-\beta$ is 31.17 MW $(1-\beta=0.3)$, which is smaller than the mean value. With the risk increasing, the target profit which a WPP can realize also increases. This is in accordance with the notion that high risk leads to high profit. In addition, the CPS can also help a WPP to set appropriate target values, for example, when a WPP is willing to face very low risk $(1-\beta=0.1)$, then the maximal reasonable target profit is $521.46 €$. If the target profit is set higher than $521.46 €$, the risk the WPP faces will thus increase.

Figure 5. Target profit under the CPS versus bid quantity with different $1-\beta$.

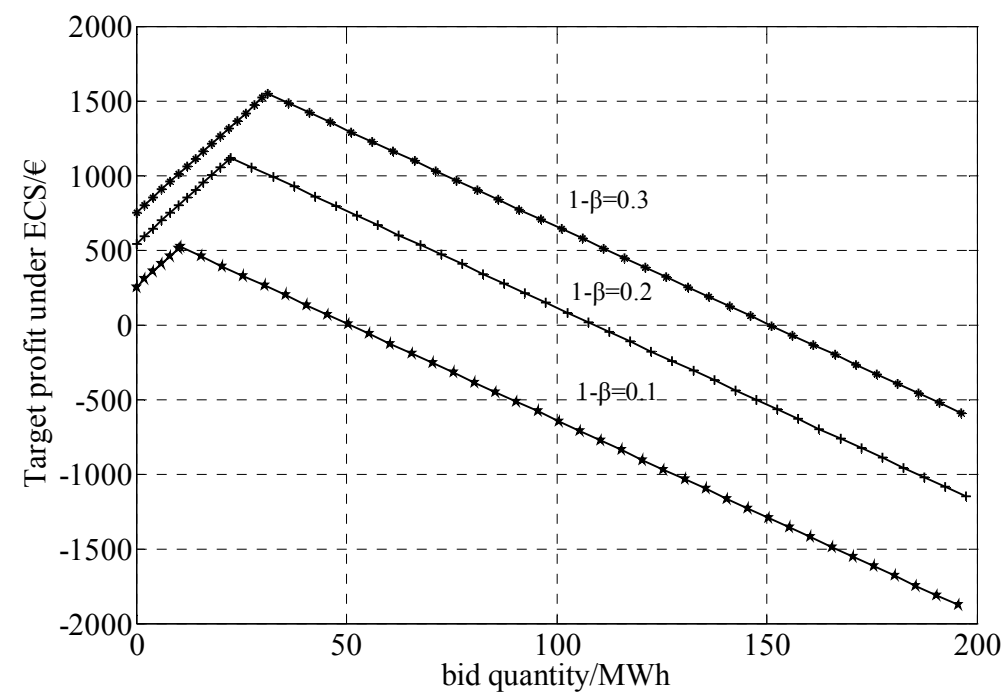

Figures 6 and 7 show how the expected profit and target profit change as a function of bid quantity with $1-\beta=0.1$ under the ECPS. As is shown, the expected profit and target profit are two conflicted objectives when the bid quantity varies from 10.48 to $57.05 \mathrm{MW}$. The expected profit increases monotonically versus the bid quantity, while the target profit decreases monotonically. 
Figure 6. Expected profit versus bid quantity under EPCS with $1-\beta=0.1$.

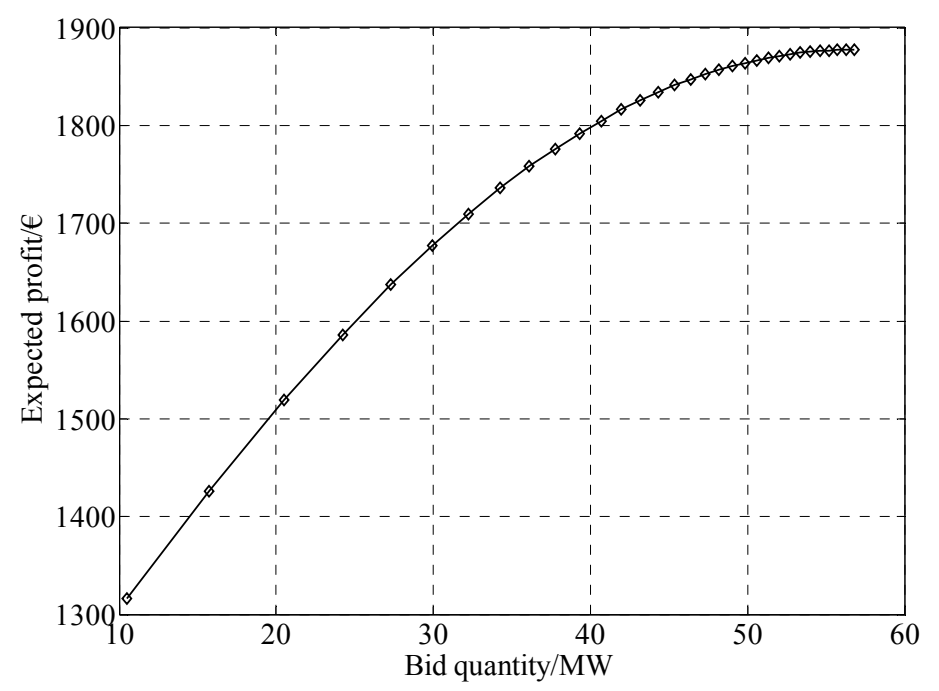

Figure 7. Target profit versus bid quantity under EPCS with $1-\beta=0.1$.

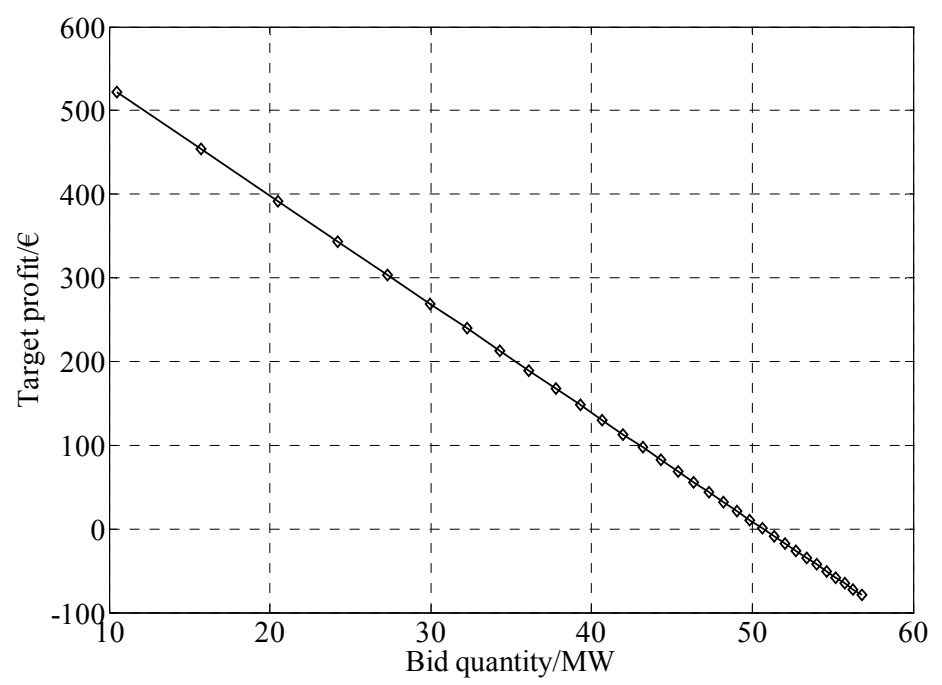

Figure 8 gives the Pareto optimal front versus different $1-\beta$ in the EPCS. The values shown in the square boxes are the optimal values of each objective. The optimal bid quantities (i.e., the best compromise solutions) are 44.31 MW $(1-\beta=0.3), 40.68 \mathrm{MW}$, and $34.28 \mathrm{MW}$, respectively. The maximal and minimal values of $F_{i}$ used here to calculate the membership function are listed in Table 4 . Based on these calculations, it can also be expected that the higher risk the WPPs face, the more profit they will obtain. 
Figure 8. Pareto optimal front versus different $1-\beta$ under the ECPS.

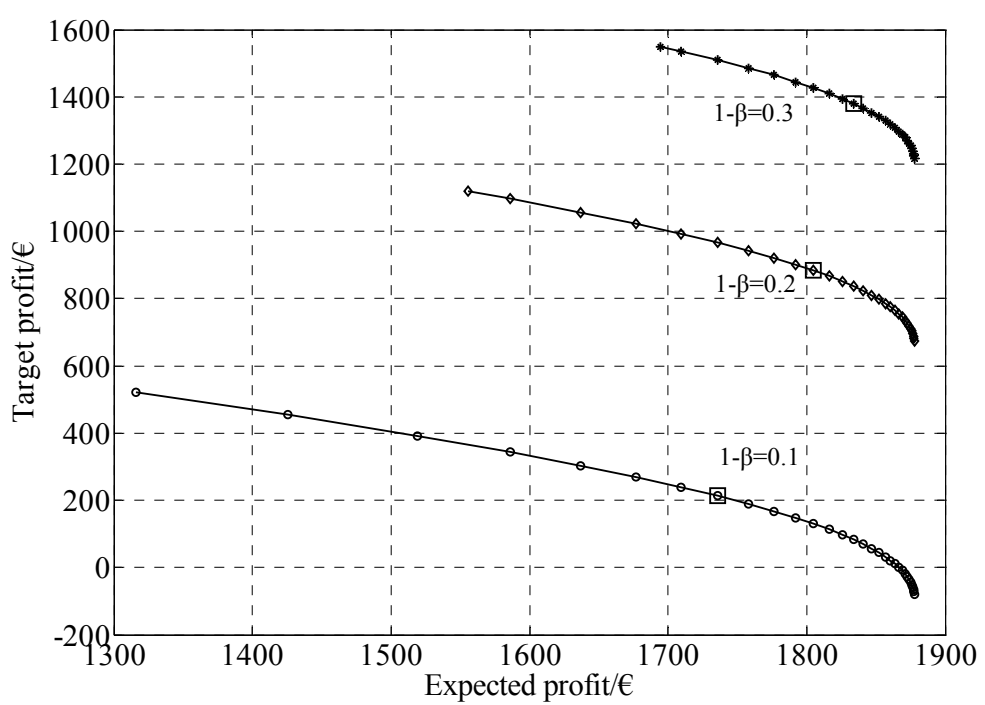

Table 4. Maximal and minimal values of single objectives and best compromise values of $\mathrm{F} 1$ and $\mathrm{F} 2$.

\begin{tabular}{|c|c|c|c|c|c|c|}
\hline $1-\beta$ & $F_{1}^{\min }(€)$ & $F_{1}^{\max }(€)$ & $F_{2}^{\operatorname{nin}}(€)$ & $F_{2}^{\max }(\boldsymbol{\Theta})$ & $F_{1}$ in square box $(€)$ & $F_{2}$ in square box $(€)$ \\
\hline 0.1 & 1316 & 1877.7 & -79.11 & 521.46 & 1747.4 & 200.72 \\
\hline 0.2 & 1555.9 & 1877.7 & 674.35 & 1119 & 1798.6 & 892.1 \\
\hline 0.3 & 1694.8 & 1877.7 & 1217.7 & 1549.9 & 1839.9 & 1379.5 \\
\hline
\end{tabular}

Figure 9 shows a comparison of the bid quantity versus risk between the CPS and the EPCS. In both strategies, the bid quantity increases when the risk increases. The CPS takes into account only the risk, while the ECPS considers both the expected profit and risk; thus, the variation range of bids under the CPS is larger than that under the ECPS and is similarly more sensitive to risk than the ECPS.

Figure 9. Comparison of bid quantity versus $1-\beta$ between the CPS and ECPS.

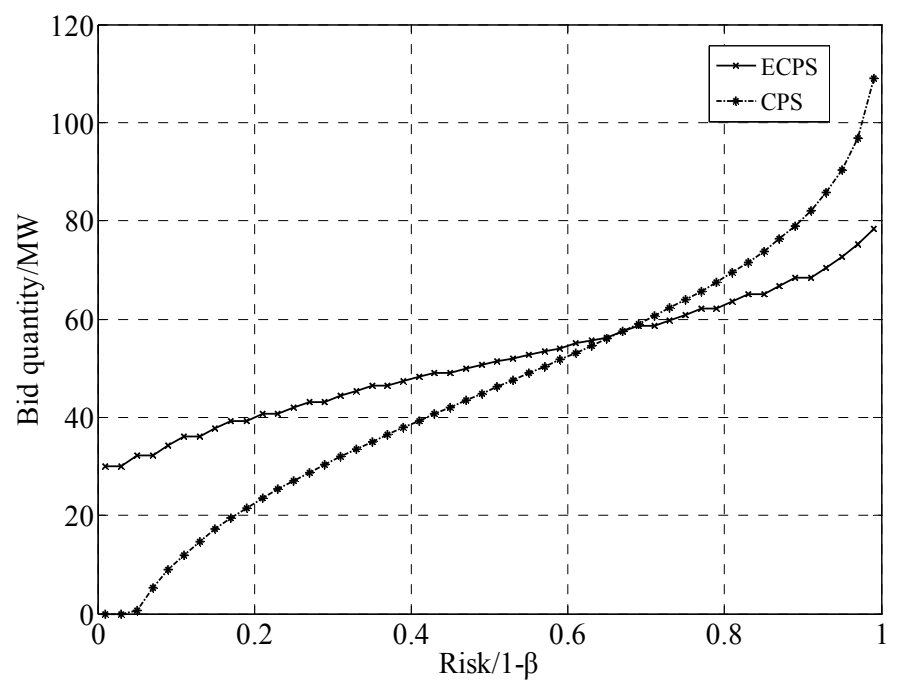

Figure 10 gives how the expected profit and target profit change as a function of the risk parameter under the CPS and EPCS. The value of risk at the cross point is 0.4143 . When the risk is larger than 
0.4143, the target profit is greater than the expected profit; this implies that WPPs face a high risk to realize the target profit. When the risk is smaller than 0.4143 , the target profit is less than the expected profit, implying that WPPs face a low risk to realize the target profit. WPPs are usually assumed to be risk-adverse; the EPCS can help to manage the risk and provide guidelines to set the risk parameter.

Figure 10. Change trend of target profit and expected profit versus risk under the ECPS.

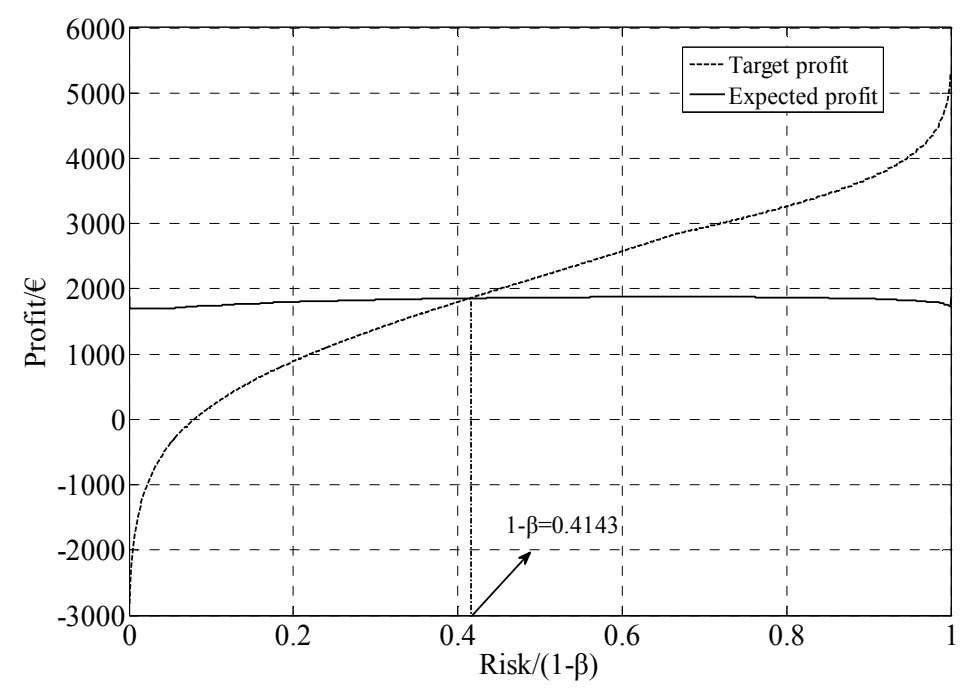

Period 2 can serve as an example; here, assume $1-\beta=0.1$, with other parameters unchanged, the impact of the standard deviation on bidding results can be obtained by varying the standard and is shown in Table 5. The accuracy of the wind power forecast has a significant effect on the three tested strategies. Under the EPS and CPS $(1-\beta=0.1)$, the smaller deviation (i.e., increased accuracy of the wind power forecast) will bring greater expected profit and target profit. The objectives under the EPS and CPS have a monotonic relation with the standard deviation. However, under the ECPS, the objective $F_{1}$ has a monotonic relation with the standard deviation, while $F_{2}$ does not, as discussed in Section 3.3.2. The values of $F_{1}$ and $F_{2}$ are calculated by the best compromise criteria.

Table 5. Comparisons of the impact of the standard deviation on bidding results.

\begin{tabular}{cccccccc}
\hline \multirow{2}{*}{$\begin{array}{c}\text { Standard } \\
\text { deviation }\end{array}$} & \multicolumn{2}{c}{ EPS } & \multicolumn{2}{c}{ CPS $(\mathbf{1}-\boldsymbol{\beta}=\mathbf{0 . 1})$} & \multicolumn{3}{c}{ ECPS $(\mathbf{1}-\boldsymbol{\beta}=\mathbf{0 . 1})$} \\
\cline { 2 - 8 } & $\boldsymbol{p}_{\boldsymbol{b}}$ & $\boldsymbol{F}_{\mathbf{1}}$ & $\boldsymbol{p}_{\boldsymbol{b}}$ & $\boldsymbol{F}_{\mathbf{2}}$ & $\boldsymbol{p}_{\boldsymbol{b}}$ & $\boldsymbol{F}_{\mathbf{1}}$ & $\boldsymbol{F}_{\mathbf{2}}$ \\
\hline 4.32 & 47.33 & 2201.5 & 39.96 & 1987 & 43.87 & 2180.9 & 1936.3 \\
14.18 & 51.49 & 2062.7 & 27.33 & 1358.7 & 0 & 2062.7 & 1974 \\
24.04 & 55.66 & 1923.9 & 14.69 & 730.46 & 0 & 1923.9 & 1773.6 \\
33.90 & 59.83 & 1785.1 & 2.055 & 102.19 & 0 & 1785.1 & 1573.1 \\
43.76 & 63.99 & 1646.3 & 0 & -663.30 & 33.11 & 1483.8 & -1092.8 \\
\hline
\end{tabular}

We now discuss the optimal bidding strategy for the entire day. Figure 11 shows that the bid quantity under the EPS is the greatest among three strategies, and also the closest to the mean value of the forecast. The EPS is mainly driven by the standard deviation of the wind power forecast and the relationship among the $\mathrm{MCP}$, the price for positive energy, and the price for negative energy. Under the CPS, aside from the relationship among the prices and the standard deviation, the bid quantity is also strongly correlated to the risk. The bid quantity under the CPS with $1-\beta=0.1$ is the lowest, as 
shown in Figure 11. The ECPS is the compromise of EPS and CPS, and takes into account both the expected profit and target profit. WPPs tend to bid a higher quantity than that under the CPS and less than that under the EPS.

Figure 11. Bid quantity with 24 hours.

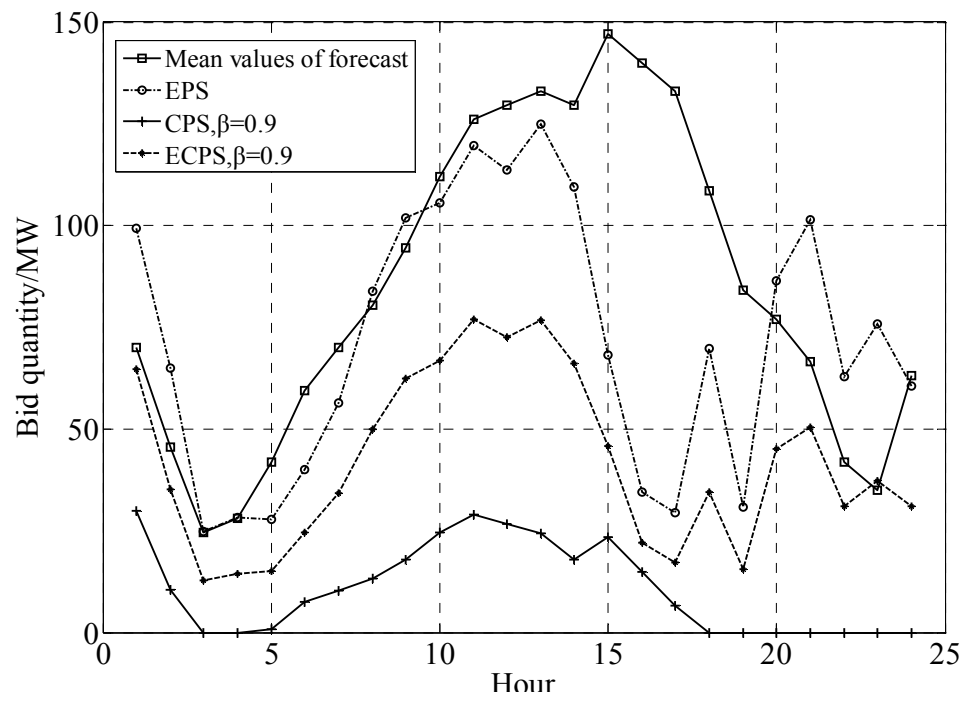

\section{Conclusions}

Due to the stochastic nature of wind resources, wind power producers are sometimes required to pay for imbalance costs caused by deviations between bids in the day-ahead market and the real power generated in the real-time market. This article has developed three different bidding strategies for wind power producers to use when participating in the day-ahead market. The EPS aims to maximize the expected profit, and the CPS calculates the target profit considering the risk which is defined as the probability that target profit cannot be realized. The ECPS is formulated as a multi-objective model. In the test case, we have discussed the optimal bids in the day-ahead market under three strategies. The following conclusions are reached: (1) The bid quantity under the EPS is highly dependent on the mean value and standard deviation of wind forecast, and also the MCP, the price for positive energy, and the price for negative energy; it is also the closest to the mean values of wind forecast. The EPS is suitable for WPPs to use when WPPs are risk-neutral; (2) Besides the parameters mentioned above, the bid quantity under the CPS is strongly correlated to the risk, and is the farthest from the mean value of wind forecast. The ECPS, which combines both the EPS and CPS, tends to bid a higher quantity than that under the CPS and less than that under the EPS; (3) Both the CPS and ECPS consider the risk and provide an alternative method for risk management; (4) The ECPS acknowledges the significance of the relationship between expected profit and target profit, and can help to set appropriate risk parameters for WPPs.

Finally, it should be pointed out that our article does not discuss the prediction techniques for prices and wind power in detail. However, high accurate prediction techniques are more helpful for WPPs to make better bidding strategies. The state-of the-art prediction tools enable WPPs to bid to the market, but of course further research is conducted to further improve the accuracy. 


\section{Acknowledgments}

This work was partially supported by National Natural Science Foundation of China (60974101, 60736027, 60921003).

\section{References}

1. Holttinen, H. Optimal electricity market for wind power. Energy Policy 2005, 33, 2052-2063.

2. Sánchez, I. Short-term prediction of wind energy production. Int. J. Forecast. 2006, 22, 43-56.

3. Gao, Y.L.; Pan, J.Y.; Ji, G.L.; Gao, F. A time-series modeling method based on the boosting gradient-descent theory. Sci. China Technol. Sci. 2011, 54, 1325-1337.

4. Usaola, J.; Angarita, J. Bidding Wind Energy under Uncertainty. In Proceedings of the International Conference on Clean Electrical Power, Capri, Italy, 21-23 May 2007; pp. 754-759.

5. Bathurst, G.N.; Weatherill, J.; Strbac, G. Trading wind generation in short term energy markets. IEEE Trans. Power Syst. 2002, 17, 782-789.

6. Fabbri, A.; Roman, T.G.S.; Abbad, J.R.; Quezada, V.H.M. Assessment of the cost associated with wind generation prediction errors in a liberalized electricity market. IEEE Trans. Power Syst. 2005, 20, 1440-1446.

7. Pinson, P.; Chevallier, C.; kariniotakis, G.N. Trading wind generation form short-term probabilistic forecasts of wind power. IEEE Trans. Power Syst. 2007, 22, 1148-1156.

8. Matevosyan, J.; soder, L. Minimization of imbalance cost trading wind power on the short-term power market. IEEE Trans. Power Syst. 2006, 21, 1396-1404.

9. Pousinbo, H.M.I.; Mendes, V.M.F.; Catalao, J.P.S. A stochastic programming approach for the development of offering strategies for a wind power producer. Electr. Power Syst. Res. 2012, 89, $45-53$.

10. Galloway, S.; Bell, G.; McDonald, J.; Siewierski, T. Managing the risk of trading wind energy in a competitive market. IEE Proc.-Gener. Transm. Distrib. 2006, 153, 106-114.

11. Xue, Y.S.; Venkatesh, B.; Chang, L.C. Bidding Wind Power in Short-Term Electricity Market Based on Multiple-Objective Fuzzy Optimization. In Proceedings of 21st Canadian Conference on Electrical and Computer Engineering, Niagara Falls, Canada, 4-7 May 2008; pp. 1135-1138.

12. Dukpa, A.; Duggal, I.; Venkatesh, B.; Chang, L. Optimal participation and risk mitigation of wind generators in an electricity market. IET Renew. Power Gener. 2010, 4, 165-175.

13. Botterud, A.; Wang, J.; Bessa, R.J.; Keko, H.; Miranda, V. Risk Management and Optimal Bidding for a Wind Power Producer. In Proceedings of IEEE Power and Energy Society General Meeting, Minneapolis, MN, USA, 25-29 July 2010; pp. 1-8.

14. Botterud, A.; Zhou, Z.; Wang, J.H.; Bessa, R.J.; Keko, H.; Sumaili, J.; Miranda, V. Wind power trading under uncertainty in LMP markets. IEEE Trans. Power Syst. 2012, 27, 894-903.

15. Morales, J.M.; Conejo, A.J.; Pérez-Ruiz, J. Short-term trading for a wind power producer. IEEE Trans. Power Syst. 2010, 25, 554-564.

16. Rahimiyan, M.; Morales, J.M.; Conejo, A.J. Evaluating alternative offering strategies for wind producers in a pool. Appl. Energy 2011, 88, 4918-4926. 
17. Moreno, M.A.; Bueno, M.; Usaola, J. Evaluating risk-constrained bidding strategies in adjustment spot markets for wind power producers. Int. J. Electr. Power Energy Syst. 2012, 43, 703-711.

18. Catalao, J.P.S.; Pousinho, H.M.I.; Mendes, V.M.F. Optimal offering strategies for wind power producers considering uncertainty and risk. IEEE Syst. J. 2012, 6, 270-277.

19. Dent, C.J.; Bialek, J.W.; Hobbs, B.F. Opportunity cost bidding by wind generators in forward markets: analytical results. IEEE Trans. Power Syst. 2011, 26, 1600-1608.

20. Wang, Q.F.; Guan, Y.P.; Wang, J.H. A chance-constrained two-stage stochastic program for unit commitment with uncertain wind power output. IEEE Trans. Power Syst. 2012, 27, 206-215.

21. Munoz, J.I.; Contreras, J.; Caamano, J.; Correia, P.F. A decision-making tool for project investments based on real options: the case of wind power generation. Ann. Oper. Res. 2011, 186, 465-490.

22. Doherty, R.; O'Malley, M. A new approach to quantify reserve demand in systems with significant installed wind capacity. IEEE Trans. Power Syst. 2005, 20, 587-595.

23. Al-Awami, A.T.; El-Sharkawi, M.A. Coordinated trading of wind and thermal energy. IEEE Trans. Sustain. Energy 2011, 2, 277-287.

24. Castronuovo, E.D.; Pecas-Lopes, J.A. On the optimization of the daily operation of a wind-hydro power plant. IEEE Trans. Power Syst. 2004, 19, 1599-1606.

25. Abido, M.A. Environmental/economic power dispatch using multi-objective evolutionary algorithms. IEEE Trans. Power Syst. 2003, 18, 1529-1537.

26. EPEX SPOT SE: Auction. Available online: https://www.epexspot.com/en/market-data/auction/ auction-table/2012-03-08/FR (accessed on 26 March 2012).

(C) 2012 by the authors; licensee MDPI, Basel, Switzerland. This article is an open access article distributed under the terms and conditions of the Creative Commons Attribution license (http://creativecommons.org/licenses/by/3.0/). 